\title{
Entre la historia y la ficción: la tragedia de Guillén de Lampart en Memorias de un impostor, de Vicente Riva Palacio
}

\author{
Between History and Fiction: \\ the Tragedy of Guillén de Lampart \\ in Memorias de un impostor, by Vicente Riva Palacio
}

\author{
Verónica Hernández Landa Valencia \\ Facultad de Estudios Superiores Acatlán, UNAM \\ verohernandez12@gmail.com
}

\begin{abstract}
RESUMEN: El presente artículo analiza la forma en que la novela histórica Memorias de un impostor, de Vicente Riva Palacio, participa en la conformación del imaginario sobre Guillén de Lampart. Muestra los problemas estructurales derivados del intento de fusionar la historia y la ficción en el relato, así como los recursos a través de los cuales, a pesar de todo, se logra conformar la imagen de un héroe revolucionario cuya tragedia está destinada a conmover y persuadir al lector. Para ello se desarrolla una metodología de análisis retórico que considera la función comunicativa del discurso, así como las operaciones retóricas de la inventio (los documentos históricos y los géneros literarios con los que dialoga la novela) y la dispositio (la manera en que estos últimos se organizan en el relato). Esta metodología se complementa con herramientas de la literatura comparada y la narratología.
\end{abstract}

\author{
Palabras clave: \\ retórica; \\ novela histórica; \\ Lampart; \\ Riva Palacio; \\ imaginario colonial.
}

KEYWORDS: rhetoric;

historical novel; Lampart;

Riva Palacio; colonial imaginary.
ABSTRACT: This article analyses how the historical novel Memorias de un impostor, written by Vicente Riva Palacio, participates in the conformation of the imaginary about William Lamport. Shows the structural problems emerged from the attempt to combine history and fiction, as well as the resources that allows, despite everything, the configuration of a revolutionary hero whose tragedy can move and persuade the reader. To achieve this goal, a methodology of rhetorical analysis is developed; it considers the communicative functions of the discourse, and two rhetorical canons: the inventio (the historical documents and literary genres 
appealed by the novel) and the dispositio (the way these elements are organized in the story). This methodology is complemented with resources provided by aceptación: 30 marzo 2017 comparative literature and narratology.

Una de las personalidades más intrigantes y polémicas de la historia de México es Guillén de Lampart (1611-1659), irlandés que fue acusado de conspirar contra la Corona en la capital de la Nueva España y pasó 17 años de su vida encerrado en las cárceles de la Inquisición. Algunos historiadores se inclinan a mostrarlo como uno de los personajes representativos de la rebeldía contra el gobierno español que se gestaba en el virreinato de la Nueva España —así ocurre con Fabio Troncarelli y Natalia Silva-.$^{1}$ Otros tienden a presentarlo como un impostor o un pícaro, con ciertos rasgos de megalomanía que, como muchos personajes de la época, sólo buscaba la fama y el engrandecimiento personal —el caso de Javier Meza.

Las dificultades para conocer y delinear la identidad del personaje aparecen desde el apellido mismo, que fluctúa entre las formas: Lampart, Lamport, Lamporte o Lombardo. ${ }^{2}$ La principal fuente de información la constituyen los documentos inquisitoriales, los cuales ofrecen numerosos

1 Cabe aclarar que el trabajo de Silva Prada, a diferencia del de Troncarelli, es ajeno a los discursos maniqueos anticoloniales. Ofrece una contextualización que busca evidenciar que la identidad y las acciones revolucionarias de Lampart eran no sólo verosímiles sino posibles, en el marco de una red de irlandeses que trabajaron al servicio de la Corona española, algunos como espías en la Nueva España, pero que por una serie de cambios políticos y malentendidos, así como por falta de verdadera protección de parte de las autoridades reales, Ilegaron a circunstancias límite que los impulsaron a adoptar conductas rebeldes.

2 A lo largo de este artículo, mantengo el apellido Lampart con fines de claridad en la exposición, debido a que es el que emplea Riva Palacio en la novela objeto de mi análisis. Sin embargo, cabe advertir que la forma aceptada por los historiadores es Lamport o Lamporte, y la versión hispanizada Lombardo; en cambio, la variante Lampart, según Javier Meza González, fue usada por los inquisidores para rechazar el origen noble del personaje, apoyados en el testimonio de fray Miguel de Santa María (Meza: 21), cuyas declaraciones se encargan siempre de presentar a Guillén como un pícaro impostor que se hacía pasar por noble, siendo que procedía de una familia de simples pescadores. 
retos al estudioso: por un lado, la inquina de los inquisidores es más que evidente, sus informes presentan numerosos vacíos y un notable deseo de minimizar la importancia y calidad de Guillén de Lampart. Por otro lado, entre las declaraciones y escritos de Lampart se presentan contradicciones, exageraciones y cabos sueltos, muchos de los cuales se explican, hasta cierto punto, por el hecho de que cada testimonio responde a distintas coyunturas y motivaciones. Finalmente, los testigos Ilamados a declarar durante el proceso tampoco resultan particularmente fiables, ya sea por mostrarse demasiado interesados en exculpar al reo, o por ser enemigos suyos, o por haber recibido presiones por parte de los inquisidores para declarar de cierta manera. ${ }^{3}$

A lo anterior se suma el hecho de que toda explicación del pasado está mediada por un posicionamiento ideológico, el cual incide considerablemente en la forma de seleccionar, jerarquizar, organizar e interpretar documentos que surgieron en un contexto ideológico distinto y que se resisten al anacronismo. El mayor reto consiste en dar un sentido unitario y coherente a lo fragmentario y contradictorio, en una búsqueda de respuestas que está mediada siempre por una visión particular de la historia en su conjunto, así como por necesidades comunicativas propias de un contexto específico.

A estos problemas se enfrentó la narración inaugural del mito, la novela histórica Memorias de un impostor. Guillén de Lampart, rey de México (1872), ${ }^{4}$ de Vicente Riva Palacio, un texto que, adicionalmente, se impuso el reto de incorporar los sucesos históricos a una narrativa ficcional para resaltar la dimensión heroica de un personaje que se rebeló contra la institución eclesiástica. Esto, sin desviarse demasiado de la información

3 Apenas en los últimos quince años, Meza, Troncarelli y Silva Prada se han dado a la tarea de recabar nuevos datos que ayuden a esclarecer la identidad de Lampart, y el contexto que posibilitó su existencia.

4 A lo largo de este artículo, cito la edición de Antonio Castro Leal (1947), debido a que es de mucho más fácil acceso para quienes estén interesados en leer la novela. Sin embargo, tuve la oportunidad de consultar la edición original, publicada en la Ciudad de México por Manuel C. de Villegas en 1872, y verifiqué que los fragmentos citados en este artículo coinciden palabra por palabra en ambas ediciones; los únicos cambios en la edición de Castro Leal corresponden a la modernización en la ortografía y en la puntuación. El ejemplar de 1872 se puede consultar en el fondo antiguo de la Biblioteca Central de la Universidad Nacional Autónoma de México. 
documentada que la novela se proponía divulgar, la cual, por momentos, termina por cuestionar el carácter heroico de Lampart.

En el texto literario, las paradojas se manifiestan desde el título mismo: por un lado, un impostor; por otro, un antecedente o precursor de la independencia, que quiso coronarse rey de México. En el intento por poner a dialogar la historia y la ficción, la novela, aun sin proponérselo, propicia distintas lecturas de un mismo suceso. Así, por ejemplo, Troncarelli considera que el personaje de Riva Palacio es "un héroe iluminista y romántico a la vez, un francmasón víctima del oscurantismo de la Iglesia y un joven víctima de un corazón tosco, si no lograra, con un último esfuerzo, salvarse de la condena, como Fausto, al encontrarse con su más profundo interior" (300). Por su parte, Silva Prada asegura que a la obra de Riva Palacio se debe la percepción, en el círculo académico, de que Lampart "era un hombre bastante loco, embustero y mujeriego [...], la cual no fue otra cosa que la transposición de la representación que de Lamport hicieron los ofendidos inquisidores, blanco de su crítica" (s. pág.).

Entonces surge la siguiente pregunta: ¿de qué manera un texto que pretendía, en el marco del liberalismo reformista de 1872, exaltar a un héroe que se rebela contra la institución eclesiástica, termina propiciando lecturas distintas? Antes que aportar al conocimiento del personaje histórico, el propósito de este artículo consiste en contribuir a la comprensión de las formas en que fue construido en el discurso literario.

En este marco, analizaré algunas estrategias a partir de las cuales la novela de Riva Palacio incorpora la historia a un relato de ficción para, desde una perspectiva poética, Ilenar los vacíos y ofrecer una imagen de Lampart que sirviera como vehículo para difundir un posicionamiento particular frente al acontecer histórico. Mostraré que dichas estrategias involucran ciertas formas de transtextualidad que provocan que las voces de distintos textos y géneros discursivos, con la retórica que les es propia, se manifiesten en la estructura Memorias de un impostor; esto deriva en tensiones al interior del texto, pues algunas de estas voces tienden a cuestionar la imagen de mundo que se proponía difundir la obra de Riva Palacio.

Para alcanzar este objetivo, emplearé una metodología de análisis retórico, siguiendo las propuestas de Antonio García Berrio, Tomás Albala- 
dejo y José María Pozuelo Yvancos. ${ }^{5}$ Procederé, en primer lugar, a explicar el contexto en el que surge la novela, los propósitos comunicativos que podía perseguir en el mismo, el prestigio y las tendencias ideológicas y literarias del autor, así como las estrategias mercadotécnicas que favorecen la credibilidad del discurso novelesco en términos de su contenido histórico.

Posteriormente, en el nivel de la inventio —entendida como la consideración de las "circunstancias inherentes a la cuestión" y un "inventario de conocimientos y hechos pertinentes al saber del retor" (García Berrio: 32 _- retomaré los argumentos que constituyen la base ideológica de la novela y que, en la época de Riva Palacio, servían para promover el rechazo a la Iglesia como institución y fomentar la emancipación mental de la sociedad. Asimismo, tendré en cuenta los sucesos históricos y algunos documentos a partir de los cuales se conforma el relato. Además, consideraré las formas narrativas, propiamente literarias, con las que dialoga esta novela histórica, y a través de las cuales se construyen distintas formas de explicación del mundo. Se observarán, pues, distintas formas de relación transtextual, desde la intertextualidad directa (citas y paráfrasis) e indirecta (alusiones textuales, tópicas, metafóricas y estructurales), hasta relaciones architextuales (Genette 1982: 8-13; Pimentel 1993: 224-225).

5 Estos teóricos se han esforzado en promover un modelo general de análisis del discurso basado en la retórica, considerando que ésta se ha encargado de explicar los principios generales de construcción del discurso que siguen vigentes hasta nuestros días, tales como el propósito comunicativo, las consideraciones en torno al contexto de enunciación en relación con los efectos persuasivos que se busca alcanzar (docere, movere, delectare), y las operaciones constituyentes del discurso (inventio, dispositio y elocutio). Según García Berrio, esta base puede ser vinculada con las aportaciones propias de las teorías de los siglos xx y xxI en torno a distintos tipos de discursos, llegando así a una "integración interdisciplinar" (14). En el caso de la literatura, el estructuralismo, la narratología y la pragmática literaria contribuyen a ampliar planteamientos que ya habían sido esbozados en la retórica clásica (la gramática del texto, la dispositio y la función comunicativa, respectivamente). En el presente artículo, además de considerar la función comunicativa en una circunstancia específica, a nivel de la inventio, y de la interdiscursividad que involucra (Albaladejo: 28), me apoyaré en algunas nociones propias de la literatura comparada desarrolladas por Genette y puntualizadas por Pimentel, así como en las reflexiones de Bajtín en torno a los géneros discursivos. Asimismo, tomaré en cuenta la distinción entre historia y discurso, que constituye un principio fundamental en los estudios narratológicos y que tiene una clara relación con la distinción retórica, relativa a la dispositio, entre ordo artificialis y ordo naturalis. 
En el nivel de la dispositio, u organización macrotextual, analizaré la forma en que dichos elementos se articulan a lo largo del relato para, en un principio, dar mayor relevancia al carácter heroico y trágico del personaje, así como a la dimensión antiinquisitorial de su rebeldía. Evidenciaré que, con estos recursos, la novela fomenta la empatía y la compasión por parte del lector, de tal forma que el pathos se convierte en el principal mecanismo de persuasión, y que con él se busca fortalecer, en el contexto de la República Restaurada (1867-1877), la convicción de que la verdadera independencia de la nación depende de la secularización definitiva de las prácticas políticas y sociales. Asimismo, se verá de qué manera se introducen elementos que tienden a desestabilizar la imagen heroica y mítica del personaje y que generan disonancias en el conjunto del relato. En este sentido, se analizarán las discordancias entre lo que ocurre en la intriga y lo que se manifiesta en el discurso de los personajes, del narrador, o de los documentos citados. ${ }^{6}$

Todo esto llevará a la conclusión de que cierto tipo de recursos, los propiamente literarios, contribuyen a forjar una imagen mítica del personaje que sigue determinados fines ideológicos. En contraste, en el intento de dar a conocer sucesos propiamente históricos al lector, cuya base fundamental son los documentos inquisitoriales, éstos terminan por influir inevitablemente en la imagen global del personaje de ficción, que así se revela en su carácter contradictorio.

\section{Narrar el pasado desde la República Restaurada}

En lo que se refiere al contexto discursivo en el que aparece Memorias de un impostor, es necesario señalar que la República Restaurada se inaugura con la victoria de un proyecto de nación llamado liberal, cuyo programa político incluía suprimir la influencia del clero en la vida pública. Esto con el fin de, por un lado, reducir al máximo la disidencia que había llevado al país a la Guerra de Reforma y a la Intervención francesa, y, por otro, de

6 El nivel de la elocutio no se estudiará de forma independiente sino en relación con los elementos previamente señalados, considerando que las operaciones retóricas se dividen con ciertos fines analíticos, aunque en el discurso se manifiestan simultáneamente. 
eliminar prácticas sociales y económicas que se consideraban como un obstáculo para el progreso material e intelectual del país.

El periodismo contribuyó al fortalecimiento de ese proyecto político a través de publicaciones como El Siglo Diez y Nueve, La Orquesta, El Libre Pensador. A dicho esfuerzo se sumaron numerosos textos literarios, los cuales, fungiendo como una "vía de actuación y persuasión poética" (García Berrio: 37), ${ }^{7}$ se dedicaban a criticar las prácticas tradicionales de la Iglesia y su actuar en la Guerra de Reforma y en la Intervención francesa, así como a promover la transformación del clero; esto ocurre en obras como El pecado del siglo (1869), de José Tomás de Cuéllar, El Cerro de las Campanas (1868), de Juan A. Mateos, y La navidad en las montañas (1871), de Ignacio Manuel Altamirano.

En este contexto, Riva Palacio fungió como magistrado de la Suprema Corte de Justicia, como periodista y redactor del periódico La Orquesta, que se encargaba de señalar los problemas que enfrentaba el proyecto político encabezado por Benito Juárez $-y$ posteriormente por Sebastián Lerdo de Tejada-, además de historiador y novelista que, a través de sus obras, contribuyó a consolidar el nuevo orden con la difusión de una visión liberal y reformista de la historia.

Es bien sabido que Riva Palacio tuvo en sus manos los archivos de la Inquisición a principios de la década de los sesenta, y ellos le proporcionaron el material para elaborar numerosos textos sobre el pasado virreinal, entre ellos, algunos relatos incluidos en El libro rojo (1871), y varias novelas históricas. La consulta de documentos inquisitoriales se convirtió en un recurso publicitario de las novelas, cuyo contenido, de esta manera, alcanzaba un estatus de verdad histórica:

7 De acuerdo con García Berrio y Booth, la literatura en general tiene una innegable dimensión retórica. Según el primero, ésta implica la "revitalización de la actividad de movere o persuasión a través de una argumentación de valores del emisor, compartida como aceptación de estimaciones por el receptor del discurso artístico" (García Berrio: 13). Por su parte, Booth procura demostrar en su estudio que incluso los textos más polifónicos se encaminan a provocar la empatía o el rechazo del lector hacia ciertas situaciones y personajes, persuadirlo en torno a la imagen de mundo que construye la obra literaria. En el caso de la literatura decimonónica mexicana, esta dimensión retórica se ve fortalecida en la medida en que los hombres de letras seguían apelando a la función didáctica de la literatura, la cual se empleaba como un medio de transformar las conciencias e incidir en la conducta de los ciudadanos. 
Monja y casada es una novela histórica en que luce el profundo estudio que su autor ha hecho de los primitivos tiempos de la redificación de México después de la Conquista.

El autor ha tenido la oportunidad de consultar detenidamente los archivos del sangriento tribunal de la Inquisición, y de allí ha tomado el argumento de la interesante novela que anunciamos.

Los principales personajes que figuran en la obra, así como los episodios más notables que se representan en la ciudad, en el palacio de los virreyes, y en los oscuros subterráneos del Santo Oficio, son verdaderamente históricos (La Iberia, 11 de julio de 1868: 4).

Novelas como Monja y casada, virgen y mártir (1868), Martín Garatuza (1869) y Memorias de un impostor representan acontecimientos en los que la Inquisición aparece como ejemplo de la influencia nefasta que ejercía la Iglesia en la vida nacional. La primera novela se centra en mostrar la forma en que la defensa de los intereses de la Iglesia provocó el tumulto de 1624, así como la privación de la libertad y tortura de Blanca de Mejía, por parte de la Inquisición. A partir de la segunda, se sugiere el origen prehispánico de la identidad nacional a través de la figura mítica de Cuauhtémoc, cuya supuesta descendencia mestiza, la familia Carbajal, es perseguida y, en su mayoría, asesinada por el Santo Oficio, bajo la falsa acusación de realizar prácticas judaizantes.

Por su parte, Memorias de un impostor, sin dejar de lado los temas previamente desarrollados, pero ahora impregnada de las nuevas ideas positivistas, presenta a la institución eclesiástica como un obstáculo para el desarrollo científico, el cual equivale a la verdadera emancipación de la sociedad. Tal como se verá más adelante, es desde esta perspectiva que se interpreta y narra la rebelión de un personaje histórico controversial como lo fue Guillén de Lampart en una novela cuyo carácter histórico se reafirma desde los anuncios que la publicitaron. Ahí, después de advertir que el relato sobre Lampart procede de los archivos de la Inquisición, se señala que será reproducida "con todo el interés y con todo el atractivo con que el novelista sabe constituirse para el público, no en un simple cronista, tampoco en solo un romancero, sino en un verdadero historiador, que tiene el don de exhumar el pasado y ofrecerlo al presente, coronado con las flores más bellas de la imaginación y de la historia" (La Iberia, 14 de junio de 1872: 4). 
Todos estos antecedentes, conocidos por los lectores de Riva Palacio, contribuyen a perfilar el ethos del enunciador, su innegable filiación liberal, el carácter confiable y veraz de su discurso, así como las intenciones subyacentes al mismo. Si bien es innegable que el narrador de la novela no equivale al enunciador real, es bien sabido que los narradores y algunos personajes de las narrativas ficcionales decimonónicas frecuentemente fungen como álter ego del autor real, de manera que los primeros quedan asociados al ethos del segundo, y así lo reconocen los lectores que están empapados del contexto en que fue escrita la obra.

\section{La invención de una novela histórica ${ }^{8}$}

En 1867, la "Oración cívica" del positivista Gabino Barreda invitaba a superar la etapa teológica en que, según él, se hallaba todavía sumergida la sociedad mexicana, para poder acceder definitivamente al progreso de la nación, y aludía a sucesos históricos "para mirar [...] el peligro de que nos hemos librado y tomar lecciones en ese triste pasado" (85). En este contexto, varios autores, entre los que destaca José María Vigil, citaban a la Inquisición española y la persecución que llevó a cabo contra científicos como Galileo Galilei, Copérnico y Giordano Bruno, como ejemplo del pasado que no se debía repetir si lo que se deseaba era el progreso científico de la sociedad, y para afianzar la convicción sobre la conveniencia del orden político vigente en la República Restaurada.

Esta tendencia se acrecentó en 1870, cuando se publica El Libre Pensador, un periódico dedicado casi exclusivamente a criticar las prácticas tradicionales de la Iglesia y a exigir la reforma de esta última para que pudiera estar acorde con la ciencia y el progreso; algunos artículos llegaron a promover la introducción del protestantismo en México, con el argumento de que, si la religión era necesaria para la sociedad, era mejor optar por una que sí fomentara el desarrollo científico. ${ }^{9}$

\footnotetext{
8 Los elementos expuestos en este apartado serán retomados en el siguiente, donde se profundizará en el análisis e interpretación de la novela.

9 Es el caso de "Catolicismo y protestantismo", de G. Gostkowski y "La ciencia y la Iglesia", artículo sin autor, tomado de El Jornalero de la Prensa (El Libre Pensador: pássim).
} 
Como se sabe, el ejemplo constituye una forma de argumentación de carácter inductivo, en la que, a partir de un caso específico, se extraen principios generales que permiten juzgar la naturaleza de otros casos semejantes, o de la especie a la que pertenecen dichos casos. En los discursos previamente mencionados, ciertos actos arbitrarios, crueles o supersticiosos de la Inquisición son planteados como representativos del actuar de la Iglesia, de manera que los significados negativos que se atribuyen a la primera se trasladan a la segunda. Asimismo, en la medida en que las acciones de la Inquisición se ubican en el periodo colonial, a través de un proceso sinecdóquico en que la Inquisición es mostrada como la institución más representativa del periodo, éste adquiere también fuertes connotaciones negativas, se convierte en una especie de antiejemplo que sirve como punto de contraste para exaltar los logros de las políticas de la República Restaurada, que apuntan a combatir la participación de la Iglesia en la vida pública. ${ }^{10}$ Estas formas de argumentación van conformando una especie de red de alusiones tópicas de las que participa la novela de Riva Palacio en su interpretación de la rebelión de Guillén de Lampart y su relación con la Inquisición.

Algunos de los documentos en los que abreva la novela son las declaraciones que hace el propio Lampart, volcadas en la "Proclama por la liberación de la Nueva España de la sujeción a la Corona de Castilla y sublevación de sus naturales" (1640-1642), el "Pregón de los juicios justos de Dios que castigue a quien lo quitare" (1650) y el "Cristiano desagravio y retractaciones de don Guillén Lombardo" (1651). La novela se vale de paráfrasis, resúmenes, y, a veces, citas textuales extraídos de dichos documentos, los cuales son puestos en boca del personaje novelesco para trazar una biografía que parece sacada de una novela

10 Así ocurre, por ejemplo, con José María Vigil, quien asegura que la Inquisición "se apoderaba del audaz que pretendía tener razón contra los teólogos, y después de torturarle de mil maneras, si no lograba arrancarle una retractación solemne, le arrojaba moribundo a las llamas, para que expiara el crimen de pensar" (1), y después concluye: "Este siglo, sobre el cual llueven las estúpidas maldiciones de los adoradores de un pasado de horror y de miseria, es sin embargo, más positivamente cristiano [...] se ha despojado de todas esas bárbaras superfetaciones de la ignorancia para tener una idea menos imperfecta de la divinidad" (2). 
de aventuras, aunque sí incluye varios datos que pueden ser comprobables. ${ }^{11}$

En estos documentos, Lampart asegura que era descendiente de los Lamport, una familia noble reconocida por su fidelidad al cristianismo, que fue enviado a estudiar en Inglaterra, hasta que a los doce años se vio obligado a huir debido a que escribió unos textos que censuraban al rey de Inglaterra. Fue capturado por unos piratas que terminaron por reconocerlo como su líder hasta que decidió huir de ellos. Más tarde, supo del paradero de los piratas y decidió contribuir a su cristianización. El éxito de su empresa le valió el reconocimiento del conde-duque de Olivares, mano derecha del rey Felipe IV, quien a partir de entonces patrocinó su educación y le encomendó diversas misiones, como la que lo llevó a participar en la batalla de Nordlingen.

Según Lampart, fue una misión secreta la que lo condujo a la Nueva España. Aseguró en sus declaraciones que fue enviado para espiar las acciones del virrey recién nombrado, el marqués de Villena, sospechoso por sus relaciones con el duque de Braganza, y que envió numerosos informes al respecto que contribuyeron a su destitución. Más tarde, se arrepintió y decidió ayudar a Villena en su defensa, para lo cual tuvo distintas conferencias con él. En las declaraciones ante los inquisidores, Lampart asegura que entre sus trabajos estuvo descubrir la conspiración de los portugueses radicados en la Nueva España; con ese fin, escribió documentos en los que simulaba promover una insurrección, esperando que los portugueses se le acercaran, manifestándole su apoyo, y así poder desenmascararlos y denunciarlos (Meza: 81-82). En la novela de Riva Palacio se omite toda esta información, probablemente debido a que ello permitiría vincular al personaje a la Corona española de tal manera que no convenía para los fines de una narración que configura la imagen de un héroe rebelde, y no la de un delator.

Esos planes de insurrección están contenidos en el documento titulado "Proclama por la liberación de la Nueva España", que sí fueron retomados

11 El estudio de Troncarelli se centra en demostrar que muchas de las afirmaciones de Lampart sí pudieron haber ocurrido. No obstante, a veces no toma en cuenta la clave retórica bajo la cual se escribieron los discursos de Lampart, ni el hecho de que la narración está muy influida por la narrativa de aventuras de la época. 
por la novela de Riva Palacio. En este documento, Lampart manifestó que contaba con el apoyo de 500 hombres blancos, así como de indígenas y mulatos; aseguró que uno de los indígenas le proporcionaría los seIlos necesarios para falsificar documentos que facilitarían el golpe contra el virrey. Lampart prometía la abolición de la esclavitud y un gobierno democrático, en que los nativos de México lo podrían elegir libremente como su nuevo gobernante, y en el que además serían capaces de obtener puestos públicos. La lectura de este y otros documentos, por parte de Felipe Méndez, quien desconfiaba de Lampart, motivó la denuncia ante el Santo Oficio.

Para relatar las experiencias de Lampart dentro de las cárceles de la Inquisición y los motivos que se arguyeron para su prisión, Riva Palacio se apoya en el abultado expediente generado por los propios inquisidores, donde constan declaraciones de distintos testigos. Al final de la novela se incluye como apéndice la "Sentencia y ejecución de Don Guillén de Lampart", tomada de los archivos de la Inquisición. ${ }^{12}$

De estos documentos se desprende que el pretexto para que la Inquisición participara en la captura de Lampart fue acusarlo, en principio, de practicar astrología judiciaria y tratar de usar peyote para conocer el futuro (Meza: 71). Él negó las acusaciones de herejía, arguyendo que la práctica astrológica era legal y que nunca usó peyote. A sabiendas de que el motivo fundamental de su prisión eran sus planes de conspiración, volcados en la "Proclama...", para liberar a la Nueva España del dominio español y constituirse en Rey, en varias ocasiones exigió ser juzgado por un tribunal civil, mostrando en sus argumentaciones un conocimiento tan profundo de la doctrina cristiana y del derecho civil que frecuentemente puso en predicamentos a los inquisidores, tal como demuestran Troncarelli y Meza a lo largo de sus respectivos estudios.

En sus informes, los inquisidores rechazaron el origen noble de Lampart, aseguraron que era hijo de un pescador y que todo el relato sobre sí mismo era un tejido de imposturas. Sin embargo, se tomaron muy en

12 Fabio Troncarelli $(284$, n. 8) asegura que sí se trata de la transcripción del documento original. Por mi parte, he podido constatar que, parte de la información contenida en este apéndice, repite ciertos contenidos volcados en la "Proclama..." y en el "Cristiano desagravio...", que escribió el propio Lampart. 
serio al preso, y retrasaron su proceso lo más que pudieron, cuando las acusaciones de herejía contra él sólo podían dar como resultado un castigo menor.

Durante el proceso, numerosos testigos aseguraron que Lampart estaba loco y que su supuesta conspiración era sólo una artimaña producto de su megalomanía, o de las imposturas propias de un pillo mitómano que quería aprovecharse de los demás haciéndose pasar por alguien más importante de lo que era y prometiéndoles recompensas que era incapaz de cumplir (Troncarelli: 213). ${ }^{13}$ Unos le atribuyeron acciones heréticas adicionales a la astrología judiciaria, y al uso del peyote, como hacer aparecer comida y dinero; otros aseguraron que tenía una capacidad inusual de seducir a las mujeres y la atribuían a conjuros mágicos; incluso se llegó a decir que tenía un pacto con el diablo (Meza: 57-69 y 120).

Algunas de las acusaciones de impostura y megalomanía son retomadas por Riva Palacio, y ellas serán las que interfieran en la imagen heroica del personaje, sobre todo al final de la novela. En ésta, también se hacen alusiones metafóricas ${ }^{14}$ a las prácticas de astrología judiciaria: en el capítulo "Los misterios de Urania" (Riva Palacio, t. 1: 119-126), se contextualiza la conspiración de Lampart en el marco de una secta secreta de estudiosos de la ciencia y de la astrología que rinde culto al sol, la ciencia y la divinidad; ${ }^{15}$ en cambio, no se menciona nunca el peyote o cualquier otra práctica que pudiera vincular a Lampart con prácticas supersticiosas o charlatanería. La relación con el diablo y las mujeres será igualmente objeto de una alusión metafórica en Memorias de un impostor, en un sentido muy distinto al original puesto que tiende a matizar las connotaciones negativas de ambas acusaciones: el diablo será responsable del carácter mujeriego de Lampart, por el cual fracasa su empresa independentista.

13 El testigo más representativo en este sentido es Miguel de Santa María, quien parecía tener una inquina especial contra Lampart. Su testimonio es citado en numerosas ocasiones por Meza y Troncarelli.

14 Por alusión metafórica se entiende aquella "en la que el elemento aludido del hipotexto se utiliza como el vehículo, o grado manifiesto, del nuevo tenor poético, o grados construidos de la significación metafórica en el hipertexto" (Pimentel 1993: 224).

15 Es posible que los símbolos, los discursos asociados a esta secta secreta tengan mucho que ver con la masonería que practicaba Riva Palacio, o al menos con ciertas tradiciones ocultistas. Ésta es una veta de la novela que todavía queda por explorar. 
Durante su prisión, el Lampart histórico pudo convivir con los numerosos judíos que fueron acusados de conspirar contra la Corona, incluidos una tal Juana Enríquez (Meza: 95), nombre que será retomado para denominar a uno de los personajes ficcionales de quien se enamora el Lampart novelesco, y que será encerrada en las cárceles del Santo Oficio junto con su familia por prácticas judaizantes. Aunque al principio Lampart lideró a los judíos, al final se ganó su aversión, incluida la de una judía llamada Isabel de Silva que declaró contra él, y de la que supuestamente Lampart estaba enamorado (Meza: 91-113; Troncarelli: 211-212). ${ }^{16}$

Después de que los judíos fueron condenados, Lampart quedó solo en su celda y pidió un compañero, el cual le fue concedido. Éste debía fungir como espía, pero terminó siendo cómplice en la fuga planeada por Lampart. Los testimonios de este personaje, quien regresó a la Inquisición arrepentido, además de los reportes inquisitoriales, contribuyeron a reconstruir los momentos previos a la fuga y la fuga misma, los cuales son narrados con bastante fidelidad en la novela. En la fuga, Lampart perdió un tiempo precioso colocando libelos antiinquisitoriales en diversas partes de la Ciudad de México —entre los que se incluye el "Pregón de los juicios justos de Dios" - y encargándose de que llegara una denuncia contra el Santo Oficio a las manos del virrey. Quizás fueron esos retrasos los que contribuyeron a su pronta captura.

Después de la fuga de Lampart y del escándalo que ésta produjo, los inquisidores endurecieron su actitud hacia el preso. Éste, en su desesperación, se mostró cada vez más rebelde y terminó por desafiar a sus jueces en términos que la institución no podía calificar sino como heréticos y que Ilevaron finalmente a la expiación de Lampart en el patíbulo.

Estos datos son materia prima de la novela que aquí nos atañe y las voces de los inquisidores y de Lampart son contrastadas de tal manera que, según se verá más adelante, la novela procura inclinar las preferen-

16 Como un ejemplo de las distintas interpretaciones de que es objeto el personaje, para Meza, Lampart jugaba doble con los judíos: les inspiraba un espíritu de rebeldía haciéndoles creer que Lampart tenía alta importancia política y, al mismo tiempo, espiaba sus acciones y los delataba ante los inquisidores. Al final, a todos mentía (95). En cambio, para Troncarelli, Lampart había creado una alianza con los judíos que ellos terminaron por traicionar (212). 
cias y convicciones del lector hacia Lampart. No obstante, las paradojas comienzan a aparecer desde el inicio: el apellido Lampart, usado por los Inquisidores, y no el de Lombardo, empleado por Guillén, fue el elegido para denominar al personaje novelesco; también el mote de impostor es retomado desde el título mismo de la novela. Es en lugares como estos que la voz de los inquisidores termina por imponerse sobre el discurso de Lampart, generando ambigüedades en la novela.

En lo que respecta a las relaciones architextuales, propiamente literarias, que se pueden rastrear en Memorias de un impostor, cabe señalar que ésta es una novela histórica, género literario que tiene como origen la novela de aventuras. Esta última, en el mundo premoderno, se caracterizó por presentar un personaje heroico con capacidades físicas rayanas en lo sobrenatural, que se enfrenta por casualidad a una serie de peripecias o pruebas a través de las cuales demuestra su valía; frecuentemente se trata de conflictos ajenos cuya solución no beneficia directamente al héroe, por lo que, de esta manera, manifiesta su carácter desinteresado; a veces también establece relaciones vasalláticas con su dama, y algunas de las aventuras que enfrenta constituyen una prueba a su fidelidad. El paso del héroe por distintos lugares contribuye a mostrar la naturaleza del mundo que lo rodea y en el que él destaca por su singularidad. Originalmente se trataba de un mundo exótico, pero, conforme se acerca a la modernidad, el mundo novelesco se vuelve cada vez más histórico y cercano a la experiencia del hombre. En la novela histórica se retoman algunos de estos elementos, pero se articulan de tal manera que el héroe deja de parecer sobrenatural para exhibir un mundo histórico regido por la causalidad, un mundo histórico del cual él mismo es resultado (Bajtín 1989).

La novela histórica Memorias de un impostor mantiene algunos elementos propios de la novela de aventuras tradicional que no son refuncionalizados dentro de la nueva poética para favorecer la caracterización de un héroe singular y heroico, generoso y dispuesto a luchar por la mujer que ama. Esto crea ciertas tensiones al interior de la novela histórica, las cuales se amplifican a partir de la presencia de una explicación trágica de los acontecimientos. A estas tensiones se suma el hecho de que, contrario a la tendencia a mostrar un mundo siempre abierto a nuevas posibilidades de acción humana propia de la novela de aventuras y la novela histórica, 
el entramado trágico de la novela presenta un mundo cerrado que tiende a absorber y resignificar los elementos propios de los géneros previamente descritos.

La tragedia, tal como advierte Aristóteles en su Poética, para lograr el efecto catártico, debe presentar a un héroe que, después de vivir experiencias exitosas o felices, experimenta un cambio de fortuna que lo lleva a la desgracia y a la miseria (18-19). En ella, el destino frecuentemente juega un papel fundamental: los acontecimientos tienden a reafirmar su inevitabilidad, y así muestran al hombre como sujeto a fuerzas que no puede controlar. Lo anterior provoca que la tragedia tenga un carácter circular, cerrado, que la acerca al mito. Este entramado trágico es el que se encarga, en la novela de Riva Palacio, de enlazar los elementos históricos y los inventados, para generar una explicación del conjunto del acontecer.

Finalmente, cabe advertir que la novela histórica se emparenta estrechamente, en el siglo XIX, con la novela de folletín y sus estrategias de suspenso, las cuales involucran un juego de falsas apariencias que posterga el desenlace y la mostración del verdadero sentido de los acontecimientos; así se mantiene en vilo la atención de los lectores y se revela un mundo más complejo de lo que a primera vista se piensa. Esto puede ocurrir desde el título del relato. ${ }^{17}$

Esta advertencia es importante porque constituye una clave para leer el título de la novela de Riva Palacio, Memorias de un impostor. Guillén de Lampart, rey de México, sobre todo considerando que, más adelante, el narrador advierte que fueron los inquisidores los que consideraron que la historia de Lampart "era un tejido de mentiras y falsedades" (Riva Palacio, t. 2: 113). En contraste, este narrador aparenta una neutralidad cuya naturaleza impostada evidenciará el entramado mismo de la novela, pues se muestra siempre inclinado a justificar las acciones de Lampart y a destacar sus cualidades heroicas. No obstante, las paradojas no logran resolverse del todo poéticamente, y eso propiciará que la ambigüedad prevalezca.

17 Así, por ejemplo, en el desarrollo de La hija del judío (1848-1849), de Justo Sierra O'Reilly, se muestra que el personaje objeto de este epíteto no es hija de ningún judío, sino que se trata de una acusación falsa por parte de la Inquisición para apoderarse de los bienes de la joven. 


\section{La tragedia de Guillén de Lampart}

La novela inicia con un prólogo del autor, que tiene como objetivo captar la atención y la benevolencia del lector. En él se asegura la naturaleza histórica de ciertos sucesos narrados, que pueden distinguirse claramente de los ficcionales, de manera que es posible "popularizar los conocimientos científicos, evitando el escollo del fastidio" (Riva Palacio, t. 1: XVI). Llama además la atención sobre tres aspectos que aborda la novela. En primer lugar, la historia de un "irlandés que quiso coronarse rey de México" y "hacer independiente a la Nueva España" (XIV-XV). En segundo lugar, se destaca la relación de Lampart con la ciencia: "un hombre de profundos y vastos conocimientos" que incluían el dominio de distintos idiomas, el derecho, la teología, y "todas las ciencias naturales" (XV). En tercer lugar, y en evidente contraste con lo anterior, el papel de la Inquisición "en la época de la dominación española", "que todo lo abarcaba y todo lo invadía" (XV). Así, el sentido que se va atribuir al personaje queda establecido desde un principio, no como un impostor, sino como un héroe de espíritu científico, que queda contrapuesto a la institución eclesiástica.

El relato se inaugura con un acontecimiento propio de la novela de aventuras tradicional: el orden de la naturaleza se encuentra trastocado debido a que un huracán asola la Ciudad de México y, en este contexto, Guillén de Lampart funge como héroe desinteresado que "parecía dotado de una fuerza hercúlea y de una grande energía" (t. 1: 16). Gracias a estos atributos, logra salvar del incendio en las casas del Cabildo a un inválido cuya identidad desconoce, lo aleja del peligro cargándolo sobre sus hombros durante más de un cuarto de hora, sorteando distintos obstáculos y en medio del calor de las Ilamas.

Inmediatamente después de esta escena, Lampart va en busca de Rebeca, una mujer de la que está enamorado. Al ser judía, ella vive en peligro constante de ser apresada por la Inquisición. A pesar de todo, deposita sus secretos en Lampart, quien la ama profundamente y así lo demuestra en una escena propia del amor cortés, en que el héroe caballeresco establece una relación vasallática con su dama ideal, a la que ama en secreto: "tú vas conmigo a todas partes: tu imagen me guía, tu recuerdo me sostiene, tu amor me ampara; y si tengo arrojo, es porque me parece que me miras [...] si acometo una noble empresa, es porque anhelo recoger una sonrisa 
de aprobación en tus labios" (34). Con esta escena la imagen del héroe se amplifica con los valores de fidelidad, disposición de lucha ante las adversidades y tolerancia religiosa.

La novela de aventuras tradicional cumple su función inaugural al presentar a un héroe caballeresco con capacidades sobrenaturales, noble, desinteresado, capaz de arriesgar su vida por otros y fiel a sus ideales. De esta manera se propicia la empatía del lector hacia el personaje.

A continuación, se presentan distintos personajes que tendrán un papel importante en la desgracia de Lampart. El marqués de Villena, quien casualmente se enamora de Juana, lo que tendrá repercusiones en una serie de encuentros y desencuentros — propios de la novela de aventuras - entre Juana y Lampart. Fernanda Juárez de Subirá, "una viuda temible" (45), quien inicialmente estaba involucrada en la conspiración de Lampart y después le volteará la espalda al favorecer la intriga amorosa de Villena. Felipe Méndez —nombre del denunciante del Lampart histórico—, hijo del inválido a quien Lampart rescató del incendio, el cual demostrará su ingratitud al conspirar contra Lampart por envidia, y provocar su denuncia ante el Santo Oficio. A partir de las acciones de Fernanda y Felipe, la novela histórica representa el ambiente de intrigas cortesanas propias del mundo colonial, que fungen como parte de la explicación del acontecer; con esto se irá generando la impresión de que el protagonista se encontraba cercado por circunstancias adversas y se amplificará la imagen de que Lampart fue víctima de las circunstancias, imagen que se inaugura en la siguiente secuencia.

Se trata de una secuencia trágica y simbólica que enmarcará la rebelión de Lampart y los grandes sucesos históricos asociados a ella. La novela explora la faceta de mujeriego que algunos testigos atribuyeron al Lampart histórico y se nos muestra que el personaje novelesco tiene más de una enamorada. Éste explica su carácter a partir de una predestinación trágica. Asegura que, al nacer, su horóscopo le predijo:

felicidad, riqueza, honores, valor, ciencia [...] Una noche, quizá ese mismo día, mi madre soñó que el diablo llegaba junto a su lecho [...] y que le decía: "Yo soy el monarca de las tinieblas y del mal: el que todo lo puede ha bendecido a tu hijo y le ha dado de sus dones; quiero darle yo también de los míos: yo 
le señalaré para darle el poder del amor sobre los corazones de las mujeres; feliz será con ellas como ningún otro, pero esto le apartará de otros caminos y le traerá a mi reino". Y al decir esto, el diablo puso su dedo sobre mi frente, dejándome en ella una mancha rojiza (83; las cursivas son mías). ${ }^{18}$

Esta explicación sobrenatural tiende a evadir la responsabilidad del héroe en sus acciones, que no dejan de ser reproblables pero quedan matizadas, y, además, se convertirá en la explicación poética del fracaso de su rebelión: conforme avance el relato se verá, efectivamente, que cada vez que conoce a una mujer se enciende la mancha rojiza que encadena el destino de la mujer al de Lampart. Así, este personaje llega a tener relaciones con cuatro mujeres a la vez y, cuando su secreto se descubre, una mujer despechada, en venganza, denuncia la conspiración de Lampart ante los tribunales de la Inquisición.

El carácter mujeriego asociado a una explicación mítica constituye el punto de partida para vincular al personaje con elementos del mundo colonial que, simbólicamente, legitiman su rebelión, pues ellos contribuyen a crear la impresión de que Lampart cuenta con alianzas en varios sectores de la sociedad novohispana. Así, además de estar enamorado de una judía cuyo nombre aparece en los documentos inquisitoriales, sostiene relaciones con Carmen, una noble indígena que participa en la conspiración que lidera Lampart. También se enamora de doña Inés, esposa de un burócrata novohispano, y de Clara, miembro de los sectores medios de la sociedad.

Una vez que Lampart explica su sino, se muestran los detalles de la conspiración que organiza. El conde de Rojas expone el espíritu de la conspiración en un discurso de tipo deliberativo pronunciado durante una reunión secreta; se trata de una rebelión contra las instituciones que impiden

\footnotetext{
18 Quizás este pasaje esté inspirado en ciertas palabras que Diego Pinto atribuyó en sus declaraciones al Lampart histórico: "Tuvo la idea de escribir y divulgar que aquella misma noche en que murió el arzobispo, hacia media noche, se le había aparecido su sombra para decirle que había sido enviado por Dios para remediar la gran injusticia que se le había hecho, sin mostrar interés por su proceso. Decía haber venido para llevárselo lejos de allí y que le dejaría como señal de su presencia una marca de fuego, que era la señal de la cama de donde había sacado el hierro" (cit. en Troncarelli: 235).
} 
el desarrollo científico de México: "El amor a la ciencia nos reunió; pero la ciencia es la luz, y la luz es la libertad, y en la ciencia hemos visto la libertad, y la libertad comienza en la patria y no hay patria sin independencia" (122). A estos entimemas encadenados añade los antecedentes que apuntan a fundamentar semejante postura:

Las verdades de la ciencia, no lo eran para nosotros si no tenían la aprobación de nuestros amos; teníamos la obligación de creer lo que ellos querían que creyésemos, y una hoguera de la Inquisición es aún el premio del que tiene el atrevimiento de saber más que ellos; y la persecución política y religiosa es consecuencia de la duda, y un ángel armado con la espada del fuego del Santo Oficio, guarda las puertas del paraíso de la sabiduría, a cuyo umbral nadie puede llegarse sin escuchar las terribles palabras que rodean como un lema, los escudos inquisitoriales: Exurge, Domine, et judica causam tuam (122).

A continuación, enmarcada ideológicamente por esta explicación puramente ficcional, se introduce la materia propiamente histórica. El narrador pone en boca de nuestro protagonista un discurso en que se resume el contenido de la "Proclama...", donde expresa con detalle la estrategia que pretendía seguir en su supuesta rebelión, y cuyas características expliqué en el apartado anterior. En él se omite cualquier referencia a los vínculos que, según el personaje histórico, existían entre Lampart y el conde-duque de Olivares, el rey Felipe IV y el marqués de Villena. Así, la rebelión se manifiesta como un legítimo deseo de emancipar a la Nueva España, con el apoyo de distintos sectores de la sociedad que lo nombrarían rey. Al final, el personaje literario expresa una disposición al autosacrificio que reafirma su heroísmo: "si por una denuncia llegara la garra del Santo Oficio a apoderarse de mi persona, podéis descansar tranquilos, que los tormentos más espantosos, la presencia misma de la hoguera, no serían parte para arrancar de mis labios una confesión" (131).

Resulta necesario señalar que lo dicho por Lampart, más allá de que la conjuración podía ser perseguida por la Inquisición, no retoma nada de lo expresado previamente por el conde de Rojas, y es que cada discurso pertenece a una forma de intertextualidad distinta. Las palabras del conde constituyen una alusión tópica a los discursos de los liberales de la República Restaurada, incluyendo la mención a las persecuciones que 
sufrieron Copérnico y Galileo (123-124). En cambio, la "Proclama..." del Lampart histórico era una abierta rebelión contra la Corona que incluso planeaba pedir el apoyo de la Santa Sede, una vez que los acontecimientos estuvieran consumados; lo que se retoma en la novela, procurando no tergiversar el contenido de los documentos propiamente históricos, sólo son los planes para la insurrección política, sin mencionar el motivo sino únicamente el objetivo de independizar a la Nueva España y erigirse en rey.

De esta manera, los intertextos no se fusionan en un discurso unificado, más bien se yuxtaponen, lo que termina por crear inconsistencias en la imagen de Lampart. De hecho, en el resto de la novela, las actividades de Lampart se relacionan más con intrigas amorosas que con la conjuración independentista, y es que profundizar en las acciones del Lampart histórico previas a su encarcelamiento hubiera implicado evidenciar aspectos contradictorios que cuestionarían la imagen heroica y rebelde del personaje, ya fuera asociándolo a misiones de espionaje encargadas por la Corona, o a conductas que lo harían parecer un megalómano o, al menos, como embaucador de ingenuos.

No obstante, el hecho de que el Lampart novelesco realice muy pocas acciones encaminadas a la rebelión independentista y de que, antes de su encarcelamiento, no se manifieste en franca oposición al Santo Oficio, puede pasar desapercibido para el lector, debido a que las fisuras son sutiles y a que la novela ha dedicado más de cien páginas a ir amplificando la imagen de Lampart como individuo heroico y revolucionario desde distintas estrategias que apelan a diversos códigos de valores compartidos por los lectores: evoca el imaginario proindependentista, antiinquisitorial y defensor de la ciencia propios de la República Restaurada; asimismo, recurre a la admiración que produce el héroe de aventuras con sus hazañas, y a la compasión que provoca el héroe trágico.

Una vez presentado el carácter de Lampart desde estas distintas dimensiones que apuntan a captar el favor y benevolencia del lector, se desarroIlan acontecimientos propiamente históricos que sí tuvieron un impacto considerable en la vida colonial, en particular, la sorpresiva destitución del virrey marqués de Villena por parte del arzobispo Juan de Palafox, en 1642. Este suceso es más o menos contemporáneo a la escritura de la 
"Proclama..." de Lampart, y en la novela se traduce en el retraso de los planes de Guillén; también aporta verosimilitud, ya que las acciones del arzobispo se llevaron a cabo con tal secrecía que tuvieron la apariencia de una conspiración semejante a la proyectada por Lampart —la diferencia es que el arzobispo sí echó mano de documentos legales que consistían en amplios poderes otorgados por el conde-duque de Olivares-. Sin embargo, los datos históricos proporcionados por la novela no ofrecen un sustento causal que muestre la rebelión o el fracaso de Lampart en la Nueva España como el resultado de fuerzas históricas en movimiento. Al fracaso de Lampart, de hecho, sólo se le da una explicación poética, que consiste en la denuncia de una mujer despechada por la infidelidad de Lampart, e instigada por el envidioso Felipe Méndez.

Todos estos acontecimientos aparecen narrados en el libro segundo de la novela, titulado "El dedo del diablo", de manera que el desarrollo de los sucesos históricos queda enmarcado por la explicación trágica en la que intervienen fuerzas sobre las que el hombre no tiene ningún control, y es así como el mito se impone sobre la historia.

El siguiente libro de la novela narra las experiencias de Lampart en las cárceles del Santo Oficio. Ahí se omite la mayor parte de las acciones polémicas o reprobables que pudieran atribuirse a Lampart en su carácter de reo, ni siquiera se menciona que estuvo un tiempo encerrado con los judíos. Primero se dedica un capítulo completo a relatar las iniquidades que, según el narrador, cometía el tribunal de la Inquisición de manera sistemática - aprehensión derivada de denuncias anónimas y sin investigación previa, secuestro de bienes, negación del derecho a una justa defensa del preso, tortura sin excepción (t. 2: 89-95)—. Este capítulo, evidentemente, predispone al lector en favor del reo que caía en las garras del tribunal.

En seguida se nos presenta a un héroe solitario, próximo a la locura que, como Edipo, sufre terribles remordimientos después de haber pasado por la peripecia y la anagnórisis. Antes de ser apresado, Lampart fue llevado con engaños a casa de Clara, donde sus otras tres amantes espiaron las escenas amorosas que tuvieron lugar en la habitación. Guillén pudo ver padecer a todas, segundos antes de ser apresado por el Santo Oficio acusado de conspiración: 
Sabía, o suponía la causa de su prisión [...]; pero su imaginación se fatigaba buscando el nombre del denunciante, formando conjeturas [...].

Dominado por terribles impresiones, don Guillén creía algunas veces volverse loco.

El recuerdo de aquellas cuatro mujeres, a quienes él sentía amar aún con más fuego, desde que comprendió que jamás las volvería a ver, despedazaba su pecho, y le hacía verter algunas veces lágrimas de desesperación.

[...]

Ni los tormentos, ni la muerte que le amenazaba, ni el dolor que sentía al verse así arrebatado repentinamente del mundo, al que no tenía ya ni la más remota esperanza de volver, agitaban, sin embargo, tanto el alma de don Guillén, como la triste consideración del estado deplorable en que había puesto el alma pura de aquellas desgraciadas mujeres (97-98).

Esta imagen busca reafirmar la empatía con el personaje, dejando una impresión perdurable que matizará, en la percepción del lector, algunas escenas posteriores que pueden hacer cuestionable la calidad de Lampart. Con el tiempo, este último logra sobreponerse a su desesperación y empieza a proyectar planes de fuga. Se finge deprimido y mentalmente inestable para atraer la compasión del carcelero y así conseguir un compañero de celda. De esta manera conoce a Diego Pinto, a quien le cuenta su origen y todos sus antecedentes. A partir de este momento la narración se apega con bastante fidelidad a la versión del Lampart histórico, desde su origen noble irlandés, pasando por la supuesta conversión de piratas hasta el vínculo con el conde-duque de Olivares y el rey Felipe IV. Aquí el narrador pareciera reconocer a un megalómano cuya historia parece una "ficción novelesca" (t. 2: 112), y así conceder cierta razón a los inquisidores que lo juzgaban: "Realmente aparece de la narración de don Guillén, que no sólo trataba de conseguir la ayuda de Diego en su empresa, sino que le impulsaba a hacerla, el deseo de aparecer ante sus ojos como un hombre de alta importancia política y social" (128).

Sin embargo, para este momento, el lector ya está más que persuadido del heroísmo de Lampart, de su nobleza y de los altos propósitos que perseguía, y puede aceptar naturalmente que el personaje, quien para entonces ya mostraba ciertos rasgos de desesperación, pudiera hacer algunas declaraciones exageradas en torno a su persona. Así, en vez de censurarlo, se sentirá conmovido y admirado. Además, la naturaleza asombrosa, casi 
fabulosa, del personaje se reafirma con un suceso documentado, la escapatoria de las cárceles de la Inquisición, y por el desafío que representó el colocar libelos contra la Inquisición en distintas partes de la ciudad.

Al final, nada resulta más emotivo que el hecho de que, después de volver a la cárcel y pasar varios años de encierro, Lampart haya muerto en la hoguera mirando a los ojos a la única sobreviviente de sus amores pasados. Estos sucesos ocurren en el libro cuarto, titulado "Expiación", donde el héroe trágico se ve purificado luego de haber recibido el perdón de doña Inés quien, a su vez, se ve a sí misma expiando sus propias culpas. El mecanismo del pathos ejerce su influencia para que el lector resguarde en su memoria, por encima de todo, la imagen de un héroe sublime que luchó por la independencia de México, se rebeló contra la institución eclesiástica, amó con toda la intensidad de la que era capaz, y murió en el cadalso debido a un destino trágico. Así, paradójicamente, un texto que exalta el pensamiento científico recurre a estrategias no racionales para difundir una visión de mundo.

Evidentemente, el apéndice que incluye, al final de la novela, la sentencia de Lampart y los dichos de los inquisidores, puede generar una imagen contrastante frente al héroe trágico. No logra contrarrestarla, sino propiciar distintas lecturas que se inauguran con el título de la novela y son favorecidas por un narrador que manifiesta una actitud ambigua: "Opinaron los inquisidores que toda esa historia era un tejido de mentiras y falsedades inventadas por don Guillén; pero como nada prueba que esta historia fuera lo que pensaban los inquisidores, y verdad como sostenía don Guillén, el autor de este libro no se atreve a inclinarse ni a una ni a otra opinión" (113). A esto se suma una yuxtaposición de elementos que no se fusionan en una unidad, como los fundamentos científicos de la rebelión, las ambiciones de Lampart de coronarse rey, y una trama trágica que los enmarca, generando así la interpretación poética que inaugura un mito.

\section{Conclusiones}

Los relatos sobre Lampart son cada vez más diversos, y todos ellos se enfrentan al reto de dar un sentido coherente a lo fragmentario y contra- 
dictorio, partiendo de un posicionamiento ideológico particular. En este intento, surgen fisuras, tensiones, ambigüedades e incluso contradicciones derivadas de la relación dialógica que los discursos establecen con otros textos y géneros discursivos. En el caso de la novela histórica, los problemas se acrecientan debido al intento de integrar, en un solo discurso, la historia y la ficción.

Sin embargo, y a pesar de las inconsistencias y paradojas que se han evidenciado a lo largo de este artículo, la obra de Riva Palacio logró impactar en una buena parte de los lectores de su época a través de recursos poéticos y retóricos que resultaban más persuasivos que cualquier documento inquisitorial, al grado de que su obra contribuyó a que Lampart fuera considerado un protomártir de la Independencia.

El análisis retórico favorece un distanciamiento crítico frente a los relatos del pasado, y nos ayuda a comprender la forma en que personajes históricos como Lampart han sido construidos desde distintos discursos, y la manera en que han podido impactar en el imaginario social.

\section{Bibliografía}

Albaladejo Mayordomo, Tomás. "Retórica, comunicación, interdiscursividad", en Revista de Investigación Lingüística, Murcia, VIII (2005): 7-33. Artículo disponible en: <http://revistas.um.es/ril/article/view/6671/6471> [consultado el 3 de octubre de 2016].

Albaladejo Mayordomo, Tomás. Retórica. Trad. Quintín Racionero. Madrid: Gredos, 1990.

Aristóteles. Poética. Trad. Juan David García Bacca. México: Universidad Nacional Autónoma de México, 1946.

Bajtín, M. M. "Las formas del tiempo y el cronotopo en la novela". Teoría y estética de la novela. Trad. Helena S. Kriúkova y Vicente Cazcarra. Madrid: Taurus, 1989. 237-409.

Barreda, Gabino. "Oración cívica". Estudios. $3^{\text {a }}$ ed. México: Universidad Nacional Autónoma de México, 1992. 67-104.

Booth, Wayne C. Retórica de la ficción. Trad. Santiago Gubern Garriga-Nogués. Barcelona: Antoni Bosh, 1974.

Fernández Prieto, Celia. Historia y novela: poética de la novela histórica. $2^{\mathrm{a}}$ ed. Navarra: Universidad de Navarra, 2003.

García Berrio, Antonio. "Retórica como ciencia de la expresividad (Presupuestos para una retórica general)", en Estudios de Lingüística, Alicante, 2 (1984): 7-59. Artículo disponible en: <https://dialnet.unirioja.es/servlet/articulo?codigo=2799064> [consultado el 3 de septiembre de 2015]. 
Genette, Gérard. Figures III. Paris: Éditions du Seuil, 1972.

Genette, Gérard. Palimpsestes. La littérature au second degré. Paris: Éditions du Seuil, 1982.

La Iberia. Periódico de Política, Literatura, Ciencias, Artes, Agricultura, Comercio, Industria y Mejoras Materiales, México, 1867-1876.

JITRIK, Nó́. Historia e imaginación literaria. Buenos Aires: Biblos, 1995.

LAMPART, Guillén DE. "Cristiano desagravio y retractaciones de don Guillén Lombardo". Archivo General de la Nación, ramo Inquisición, vol. 1497, exp. 1, f. 8. Texto en línea, disponible en: <http://bdmx.mx/detalle/?id_cod=77> [consultado el 20 de agosto de 2016].

LAMPART, GuilléN DE. "Pregón de los justos juicios de Dios, que castigue a quien lo quitare". Archivo General de la Nación, ramo Inquisición, vol. 1497, exp. 1, f. 8. Texto en línea disponible en: <http://bdmx.mx/detalle/?id_cod=28> [consultado el 20 de agosto de 2016].

LAMPART, GUILLÉN DE. “Proclama por la liberación de la Nueva España de la sujeción a la Corona de Castilla y sublevación de sus naturales". Biblioteca Cervantina del Instituto Tecnológico de Estudios Superiores de Monterrey, Colección Conway. Texto en línea disponible en: $<$ http://bdmx.mx/detalle/?id_cod=25> [consultado el 20 de agosto de 2016].

El Libre Pensador. Periódico Político, Filosófico, Literario, México, 5 de mayo de 1870.

Martínez Luna, Esther. "Estudio preliminar", en Vicente Riva Palacio. Magistrado de la República Literaria. Una antología general. México: Fondo de Cultura Económica / Fundación para las Letras Mexicanas / Universidad Nacional Autónoma de México, 2012.

MeZa GonZÁlez, JaVIer. El laberinto de la mentira. Guillén de Lamporte y la Inquisición. México: Universidad Autónoma Metropolitana, 1997.

La Orquesta. Periódico Omniscio, de Buen Humor y con Caricaturas, México, 1861-1877.

Ortiz Monasterio, José. "Patria", tu ronca voz me repetía. Biografía de Vicente Riva Palacio y Guerrero. México: Universidad Nacional Autónoma de México / Instituto Mora, 1999.

PALTI, Elías José. La invención de una legitimidad. Razón y retórica en el pensamiento mexicano del siglo xix. México: Fondo de Cultura Económica, 2005.

Pimentel, Luz Aurora. "Tematología y transtextualidad", en Nueva Revista de Filología Hispánica. México, XLI.1 (1993): 215-229. Artículo disponible en: <http:// codex.colmex.mx:8991/exlibris/aleph/a18_1/apache_media/AE97EAT71NQD4QU6BCS5C74M8JCEB6.pdf> [consultado el 14 de enero de 2014].

Pimentel, Luz Aurora. El relato en perspectiva. Estudio de teoría narrativa. México: Universidad Nacional Autónoma de México / Siglo XXI, 1998.

Pozuelo Yvancos, José María. "Retórica y narrativa: La narratio", en Revista de Filología 2 (1986): 231-252.

QuintILIANO, MARCO FABIO. Instituciones Oratorias. Trad. Ignacio Rodríguez y Pedro Sandier. Biblioteca Virtual Miguel de Cervantes. Alicante, 2004. Web. 20 oct. 2015. <http://www.cervantesvirtual.com/obra/instituciones-oratorias--0/>. 
Riva Palacio, Vicente. Memorias de un impostor. Guillén de Lampart, rey de México. Ed. Antonio Castro Leal. 2 ts. México: Porrúa, 1946.

Sierra O’Reilly, Justo. La hija del judío. Ed. Antonio Castro Leal. 2 ts. México: Porrúa, 1959.

El Siglo Diez y Nueve, México, 1841-1896. Silva Prada, Natalia. "Orígenes de una leyenda en el siglo xVII: redes irlandesas de comunicación y propaganda política en los casos inquisitoriales novohispanos de Guillermo Lombardo y fray Diego de la Cruz", en Signos Históricos. México, XI.22 (2009). Artículo disponible en: <http://www.scielo.org.mx/scielo.php?script=sci_arttext\&pid =S1665-44202009000200001 > [consultado el 23 de septiembre de 2016].

Troncarelli, Fabio. El mito del "Zorro" y la Inquisición en México. La aventura de Guillén de Lombardo (1615-1659). Trad. Pau Oliva. Lleida, España: Milenio, 2001.

Vázquez Guillén, María Bertha. "Tras las huellas del zorro de Westford". Tesis de maestría. México: Universidad Nacional Autónoma de México, 2010.

Vigil, José María. "La ciencia y la tecnología", en El Siglo Diez y Nueve, 21 a 23 de julio de 1870: 1-2.

Verónica Hernández Landa Valencia

Doctora en Letras por la Universidad Nacional Autónoma de México, es profesora de tiempo completo en la Facultad de Estudios Superiores Acatlán donde coordina el "Seminario Retórica, Historia y Sociedad en la Narrativa Hispanoamericana del siglo XIX". También funge como investigadora invitada y miembro del comité editorial del proyecto La Novela Corta, avalado por Conacyt, con sede en el Instituto de Investigaciones Filológicas de la UNAM. Sus líneas de investigación son: retórica, novela histórica del siglo XIX mexicano, y relaciones entre literatura, historia y sociedad. Entre sus artículos publicados están: "Imaginarios y géneros discursivos: Representaciones problemáticas del periodo colonial en la novela histórica del siglo xIx mexicano", Connotas 16 (2016), y "Liberalismo, iluminismo y romanticismo: el problema de la libertad en dos novelas históricas de la República Restaurada", Literatura: Teoría, Historia, Crítica 18.2 (2016). 